\title{
Ensino de cartografia na geografia: conteúdo ou linguagem?
}

\section{Teaching cartography in geography: content or language?}

\author{
Lucas Henrique de Souza ${ }^{A}$ \\ Nathália Pereira Dourado ${ }^{B}$ \\ Patricia Helena Mirandola Garcia ${ }^{\mathrm{C}}$
}
a Bolsista Iniciação Científica - CNPq na Universidade Federal de Mato Grosso do Sul (UFMS), graduando em Geografia - Licenciatura pela UFMS.
Email: lukas_l.h.s@hotmail.com
${ }^{\text {b }}$ Mestranda do Programa de Pós-Graduação em Geografia na UFMS.
Email: nathaliaadourado@gmail.com
' Docente do Programa de Pós-Graduação em Geografia e em Ensino de Ciências na UFMS, doutora em Geografia pela Universidade Federal do Rio de Janeiro (UFRJ).
Email: patriciaufmsgeografia@gmail.com

\begin{abstract}
O presente trabalho é resultado de pesquisa no âmbito do curso de Geografia da Universidade Federal do Mato Grosso do Sul (UFMS) na área de Ensino que resultará em um trabalho de conclusão de curso. O objetivo é compreender como a Cartografia, enquanto a forma de representar o espaço geográfico, é trabalhada em sala de aula. Duas abordagens são possíveis de observar na prática de ensino da Cartografia: uma como conteúdo técnico e conceitual e outra como linguagem gráfica que permite a leitura e interpretação do mundo e suas relações por meio dos mapas. Para que seja possível essa avaliação, foram adotados os seguintes procedimentos metodológicos: revisões bibliográficas e observação in loco da prática docente para a coleta e análise dos dados, objetivando entender a concepção da Cartografia concebida pelo professor em sala de aula. O resultado permite entender a forma como é trabalhada a Cartografia, definindo, portanto, seu papel para a Geografia escolar.
\end{abstract}

Palavras-chave: ensino, geografia, cartografia, prática docente.

This work results from a research on the teaching field that will comprise an undergraduate thesis in the course of Geography of the Universidade Federal do Mato Grosso do Sul. Considering that the practice of teaching Cartography may occur in two different manners - either as a technical and conceptual content or as a graphic language that allows reading and interpreting the world and its relations through maps, this study sought to understand how Cartography, as a way of representing geographical space, is addressed within the classroom. With this end, data were collected and analyzed by bibliographic reviews and in loco observation of the teaching practice. The results indicate how teacher address Cartography, thus defining its role for school Geography.

Keywords: teaching, geography, cartography, teach practice. 


\section{INTRODUÇÃO}

A Cartografia é um dos recursos fundamentais para a Geografia, e tem como objeto de estudo o espaço geográfico, desde sua sistematização como ciência até os dias atuais. Sendo assim, é importante a discussão sobre o ensino e a utilização da Cartografia em sala de aula para a espacialização dos fenômenos apresentados durante todo o processo de ensino e aprendizagem. Com essa ferramenta, é possível um entendimento da totalidade e complexidade dos processos, articulando escalas e promovendo a compreensão do seu próprio espaço, dentre outros fatores a serem mencionados.

A prática docente é o motor desse processo, o sujeito que desenvolverá a aula e o papel da Cartografia no ensino de Geografia. Entretanto, há duas abordagens possíveis em cartografia. Uma é conteúdo técnico e científico que trabalha conceitos como orientação, escala, localização e implementação, compondo uma parte da matéria do corpo de ensino geográfico. Outra abordagem possível é seu uso como linguagem, dando origem ao processo de alfabetização cartográfica que se inicia no ensino básico até o Ensino Médio. As duas abordagens podem ser trabalhadas pelo docente a partir da sua concepção da Cartografia.

O presente trabalho é resultado de pesquisa no âmbito do curso de Geografia da Universidade Federal do Mato Grosso do Sul (UFMS). O objetivo do trabalho é compreender como a Cartografia é trabalhada em sala de aula, partindo do pressuposto de que há dois caminhos possíveis para a Cartografia ser apresentada: como um conteúdo e como uma linguagem gráfica alfabetizada que permite a leitura e interpretação do mundo e as relações entre o homem e a natureza que concebem o espaço geográfico, sendo o mapa um elemento fundamental para o entendimento desse espaço e sua complexidade e elemento chave para a formação de um sujeito social crítico diante o mundo em que vive. Para a observação em questão, são realizadas observações das práticas docentes a partir de roteiro que norteia os elementos-chave a serem observados, como o uso e leitura dos mapas aplicados aos conteúdos geográficos e os conceitos técnicos da Cartografia para o entendimento de um mapa e sua estrutura composta, interpretando sua representação do espaço. As observações geraram dados que foram tabulados e analisados, permitindo chegar a um resultado claro sobre o uso da Cartografia em sala de aula e possíveis caminhos a serem tomados para melhorar a prática cartográfica no ensino de Geografia.

\section{A PERSPECTIVA DA CARTOGRAFIA PARA O ENSINO}

A Cartografia está consolidada atualmente como uma ciência que aborda estudos sobre a produção e a leitura de mapas, expressando informações sobre o espaço tridimensional em um plano bidimensional através de técnicas de redução para que o entendimento da realidade seja possível em um papel ou cartaz. Em um cenário de novas tecnologias, a Cartografia possui uma gama de possibilidades de representação, como símbolos, orientação, cores e formas.

Seu surgimento antecede a escrita, sendo, assim, a primeira forma de linguagem de comunicação, expressão e registro de informações sobre os espaços. Seu foco era a descrição e localização de recursos essenciais para a sobrevivência naquele contexto histórico, como coloca Santos et al. (2011, p. 3):

No mundo primitivo buscavam-se diversas formas de relacionar-se socialmente, estes já desenhavam nas rochas numa comunicação não verbal que eram as pinturas rupestres (arte de pinturas feita nas paredes das cavernas pelos homens pré-históricos) que serviram por muito tempo como forma de comunicação e era a maneira pela qual por meio de desenhos representam o espaço em que viviam.

Durante seu processo histórico de aprimoramento e, com os avanços tecnológicos, a Cartografia foi explorada em diversas categorias de atividades nas formas de representar espaços da realidade reduzidos no papel para administração e exploração. Nota-se que, além de servir como meio de comunicação e administração, ela também foi responsável por descobertas inovadoras na ciência do espaço por povos que só conheciam alguns continentes, mas que já conheciam o formato do planeta, como aponta Santos et al. (2011). Logo, os mapas se tornam ferramentas para o registro de observações, sistematizando descobertas a serem usadas como produto final para fins do conhecimento geográfico, bem como uma forma de comunicação que atua em diversas atividades da sociedade a fim de representar as ações humanas no espaço.

O potencial político da Cartografia ganha destaque como poder a partir de sua utilização nas conquistas de territórios, servindo ao Estado e aos seus interesses políticos entre os séculos XV e XVI, perpassando vários períodos e servindo a vários tipos de ideologias construídas em períodos como a Grécia Antiga, Idade Média e Idade Moderna. Ela serviu também para períodos históricos 
marcantes, como a emergência das lutas por territórios até o desencadear da Primeira Guerra Mundial, no início do século XX. Mas, para esses serviços, havia exigência de mapas qualificados para representar as informações mais importantes dos territórios e dos países, demandando o aperfeiçoamento técnico dos mapas, objetivando a expansão territorial e a conquista do poder. Dessa forma, a Geografia já concebia a Cartografia como importante, uma vez que, desde seu surgimento, contribuiu para a expansão de descobertas do homem sobre o espaço e para entender e representar o espaço geográfico. Assim, a contribuição da Cartografia fundamenta-se a partir de todo o contexto histórico sobre o homem e sua relação com o espaço, representando informações, trajetos, objetos e recursos naturais. Tudo o que há no espaço tem um significado que pode ser apresentado em forma de signos em um mapa, materializando, desta forma, o espaço em um papel. Isso exige do pensamento a transformação do signo em significado. Assim, a Cartografia como ciência parte de teorias e conjuntos de procedimentos até chegar ao leitor por meio de um conjunto de símbolos, cores e formas que se estruturam para a informação que o profissional quer transmitir sobre o espaço, como afirma Mirandola (2010, p. 18) sobre o conceito da Semiologia Gráfica:

A teoria da Semiologia Gráfica trabalha com o nível monossêmico de imagens, construindo um sistema semântico pelas regras relacionadas aos signos. Segundo a teoria, um componente de mapa é uma tipologia de informação mapeada. Os componentes possuem características de organização, comprimento e modo de implantação. A eles são associadas variáveis visuais (tamanho, cor, granulação, valor ou intensidade, orientação e forma) que são os elementos gráficos para transcrever as relações entre os dados do mundo real, atributos dos lugares ou espaços, o que terá o potencial de revelar o conteúdo da informação, facilitando a compreensão em prol do conhecimento estruturado da realidade.

Segundo a autora, esse conjunto de componentes e sua organização são elementos que podem transcrever informações da realidade a partir de uma combinação sistematizada e coerente com o que será representado no papel. No ensino, os mapas têm o potencial de transmitir informações reais de diferentes escalas para o aluno, para que, além de entender o espaço, compreenda aquele em que vive, ou seja, permite que o aluno assimile o abstrato e o distante como uma realidade próxima e influente, partindo da totalidade do espaço geográfico multiescalar (MIRANDOLA, 2010).
A ciência que representa o espaço evidenciava sua importância para a sociedade servindo para discussões em outras áreas de estudos, sendo utilizada principalmente para a Geografia e o seu ensino, como afirma Santos et al. (2011). Contudo, para seu entendimento no âmbito escolar, é necessária uma linguagem visual, possibilitando uma leitura para a compreensão da realidade.

Assim como a Geografia, outras ciências apropriam-se da utilização de mapas como ferramenta para espacializar e representar informações sobre elementos no espaço, por exemplo, a Sociologia, que estuda a sociedade, e a Biologia, que estuda a vida e os organismos vivos. Ambas as áreas estudam elementos do espaço, possíveis de serem representados em uma carta, qualificando as análises e as discussões. Contudo, como outras ciências que estudam elementos do espaço e utilizam a linguagem dos mapas para expressar visualmente essas unidades, a Geografia concebe o espaço como seu objeto de estudo, ou seja, a linguagem cartográfica é indispensável em seus estudos e, principalmente, em seu ensino.

Devido a esse processo de desenvolvimento e aperfeiçoamento da Cartografia e a significação de seu objetivo para a evolução da Geografia, sua relevância para o ensino é demonstrada de forma que o aluno em seu cotidiano vive a Cartografia, articulando diferentes escalas e produzindo o espaço. Realizando trajetos de casa para a escola, para a casa dos amigos e para o mercado, ou seja, com a rotina desses trajetos é possível o aluno dominar o lugar e obter consciência de localização em seu espaço, partindo de uma escala local para uma escala global, como cita Callai (2000), podendo alcançar o entendimento de fenômenos mundiais. Porém, antes disso, é preciso compreender seu lugar como ponto de partida. Cavalcanti (2010) complementa ao dizer que:

O lugar deve ser referência constante, levando ao diálogo com os temas, mediando a interlocução e a problematização necessária à colocação do aluno como sujeito do processo. Ao estudar o lugar, pode-se atribuir maior sentido ao que é estudado, permitindo que se façam relações entre a realidade e os conteúdos escolares. (p. 6)

Contudo, só será possível o aluno ver a referência local e global a partir de um mapa que apresente a articulação de espaços com escaladas distintas, ou seja, o uso da Cartografia e seus recursos para superar a abstração dessas referências e entender o espaço em que vive e todas suas influências. Para o entendimento da produção espacial, a Geografia como disciplina escolar, tal como a 
linguagem visual, tem por objetivo a capacidade de leitura, interpretação e compreensão do espaço produzido, como apresenta os Parâmetros Curriculares Nacionais (PCN):

Ler, analisar e interpretar os códigos específicos da Geografia (mapas, gráficos, tabelas etc.), considerando-os como elementos de representação de fatos e fenômenos espaciais e/ou espacializados. Reconhecer e aplicar o uso das escalas cartográfica e geográfica como formas de organizar e conhecer a localização, distribuição e freqüência dos fenômenos naturais e humanos. (BRASIL, 1997, p. 34)

Os mapas possibilitam ter domínio espacial e sintetizar os fenômenos do cotidiano. Assim, no entendimento do seu espaço, o estudante pode evoluir para uma realidade mais complexa, articulando escalas espaciais, como salienta Simielli (2007) e Cavalcanti (2010). Nesse caminho, o Ensino Fundamental I é destacado como sendo um processo de base estrutural para o ensino e, na Geografia, o alicerce para concretizar a alfabetização da linguagem cartográfica para a leitura e interpretação de mapas e gráficos. Sendo assim, segundo Simielli (2007, p. 95):

para o ensino fundamental, com alunos de $1^{\mathrm{a}}$ a $4^{\mathrm{a}}$ série, trabalhar basicamente com a alfabetização cartográfica, pois este é o momento em que o aluno tem que iniciar-se nos elementos da representação gráfica para que possa posteriormente trabalhar a representação cartográfica.

Eventualmente, nessa caminhada alicerçada com o Ensino Fundamental I, será possível para a Geografia explorar do aluno sua capacidade de entender o espaço em sua complexidade. A partir da alfabetização nos anos iniciais, a criança desenvolve as seguintes noções de imagem: tridimensional e bidimensional, visão vertical e oblíqua, além também da lateralidade, essencial para a aprendizagem inicial e que servirá para a orientação usada pela cartografia Simielli (2007). Logo, a Cartografia, como uma ciência, se torna uma ferramenta para outras áreas do conhecimento, como a Geografia, que dispõe para a representação dos fenômenos espaciais produzidos pela relação do homem e natureza, tornando-se uma linguagem para a metodologia de ensino no âmbito escolar.

\section{Conteúdo OU LINGUAGEM}

Para a discussão da Cartografia e sua prática de ensino, é fundamental a análise das aulas ministradas, observando o papel da Cartografia para o professor e como ela será concebida pelo discente. Diante disso, o processo de ensino e aprendizagem dos conteúdos da Geografia é extenso, partindo de temas da área física, como clima, relevo, recursos hídricos, solo etc., até a área humana, como população, política, economia etc., elementos constituintes do espaço geográfico e de sua estrutura diante da complexidade da relação homem e natureza. Nesse cenário, o papel da Cartografia é espacializar esses elementos, destacando os laços dessa relação.

Ademais, a Cartografia expressa de forma representativa a complexidade desse espaço, permitindo ao aluno a superação da abstração espacial e o entendimento dos fenômenos a partir do uso da linguagem cartográfica e dos conhecimentos prévios de espaços vividos em seu cotidiano. Nos parâmetros que regem o ensino e a aprendizagem, a Cartografia mantém a proposta da prática como uma forma de linguagem que permita ao aluno ler, entender e elaborar a representação do espaço, "esta linguagem possibilita sintetizar informações, expressar conhecimentos, estudar situações, entre outras coisas, sempre envolvendo a idéia da produção do espaço: sua organização e distribuição" (BRASIL, 1997, p. 33).

O documento ainda ressalta a importância da Cartografia como linguagem, que deverá ser desenvolvida pelo professor, estabelecendo um sentido entre os conteúdos e os espaços apresentados, facilitando o entendimento concreto de um conteúdo tão abstrato em sala de aula.

A cartografia torna-se recurso fundamental para o ensino e a pesquisa. Ela possibilita ter em mãos representações dos diferentes recortes desse espaço e na escala que interessa para o ensino e pesquisa. Para a Geografia, além das informações e análises que se podem obter por meio dos textos em que se usa a linguagem verbal, escrita ou oral, torna-se necessário, também, que essas informações se apresentem espacializadas com localizações e extensões precisas e que possam ser feitas por meio da linguagem gráfica/cartográfica. É fundamental, sob o prisma metodológico, que se estabeleçam as relações entre os fenômenos, sejam eles naturais ou sociais, com suas espacialidades definidas. (BRASIL, 1997, p. 76)

Na Base Nacional Comum Curricular (BNCG), o currículo estrutura-se diante das habilidades e das competências que devem ser desenvolvidas nos alunos em cada área. Assim, a Geografia é dividida por unidades temáticas que regem o ensino e o aprendizado da disciplina. O documento é concebido como uma unidade 
para examinar as representações e a sistematização do pensamento espacial através da linguagem gráfica, mantendo a essência da cartografia para o saber geográfico. Segundo a BNCG (BRASIL, 2017, p. 363):

Espera-se que, no decorrer do Ensino Fundamental, os alunos tenham domínio da leitura e elaboração de mapas e gráficos, iniciando-se na alfabetização cartográfica. Fotografias, mapas, esquemas, desenhos, imagens de satélites, audiovisuais, gráficos, entre outras alternativas, são frequentemente utilizados no componente curricular.

Entretanto, mesmo o documento trazendo a Cartografia para ser usada como linguagem nas salas de aula, é dever do docente, ao expor e explicar os conteúdos geográficos, ter atenção e conscientização dessa linguagem para o uso e manuseio dos mapas apresentados. A construção da prática docente é fundamental no processo de formação e atuação na área, já que a prática de sala de aula determinará o papel da Cartografia para o ensino de Geografia, sendo de total responsabilidade do professor a composição de seus métodos desenvolvidos. Segundo Katuta (2000, p. 6):

o professor concebe a Geografia, como uma disciplina que tem por função descrever lugares, o uso que se fará do mapa possivelmente será o de mera localização e haverá maior ênfase na realização de descrições. Por outro lado, se o docente concebe a Geografia como uma disciplina que tem por função ensinar ou contribuir para que o aluno entenda melhor as territorializações produzidas pelos homens, o uso que se fará do mapa possivelmente será outro, pois, apesar de ser utilizado enquanto meio de orientação e localização, poderá também ser utilizado enquanto recurso que pode encetar análises e explicações geográficas da realidade mapeada.

A prática docente e as metodologias de ensino adotadas é que orientarão o papel da Cartografia. Audigier (1997) ressalta que os profissionais da educação estabelecem suas práticas não só diante dos cursos de formação, mas também diante das experiências derivadas da memória de quando eles também foram estudantes. Portanto, a Cartografia pode ser concebida de vários modos seguindo essas experiências e dependendo da metodologia adotada. "A representação gráfica, cartográfica, imagética, como qualquer produção intelectual, científica ou não, é um objeto cultural, não uma verdade absoluta; é uma construção sobre a realidade, que busca expressá-la, que busca aproximar-se dela" (CAVALCANTI, 2010, p. 19), porém, a competência pode tornar-se ineficiente para o ensino geográfico, já que a linguagem tem o objetivo de conceber a leitura e a compreensão do espaço.

A Cartografia como ciência possui uma gama de técnicas e conceitos-chaves que são essenciais para a compreensão e leitura dos mapas. Essas técnicas e conceitos são inseridos no processo de ensino e aprendizagem no início do Ensino Fundamental Ciclo II. Os conteúdos que compõem o $6^{\circ}$ ano abordam os conceitos básicos da Cartografia (orientação, localização, coordenadas geográficas), constituindo seu eixo, como analisa Katuta (2000, p. 11):

Ao examinar alguns livros didáticos de Geografia para o Ensino Fundamental, percebemos uma nítida diferença entre os mesmos. Aqueles mais conhecidos como tradicionais trazem geralmente nos primeiros capítulos, tópicos que tratam do ensino e da aprendizagem dos conteúdos de orientação e localização geográfica. Os livros mais conhecidos como críticos, muitas vezes, não trazem esse conteúdo ou o fazem "homeopaticamente", trazendo-os no final de alguns capítulos em colunas denominadas: saiba que [...], dependendo do livro didático adotado em sala de aula, o professor tem maior ou menor possibilidade de trabalhar ou não com os conteúdos acima citados.

Nesse caminho, há uma ruptura na Cartografia em sala de aula, voltando a ser contemplada somente no $1^{\circ}$ ano do Ensino Médio, criando o perfil da Cartografia como um conteúdo da Geografia concentrado em uma etapa do processo que, posteriormente, desaparece nos livros didáticos, abandonando a essência do estudo do espaço no processo de ensino.

Diante da discussão proposta para a fundamentação do papel cartográfico no ensino, destaca-se também o docente como o sujeito que tem papel fundamental no processo, pois conduzirá o ensino e conceberá o ofício da Cartografia nas aulas. Para Cavalcanti (2010), o professor tem, mediante os recursos didáticos e o currículo, a responsabilidade e a autonomia para selecionar os conteúdos e as formas de aplicação em sala de aula, definindo a prática e a metodologia usada, a fim de trazer os temas geográficos da melhor maneira possível. Diante dos dois papéis da Cartografia apresentados acima, a linguagem pode ser adotada como uma metodologia a ser usada durante todo o processo e o conteúdo como a base para a caminhada da leitura cartográfica conforme presente no currículo. Entretanto, a metodologia pode ser esquecida e o conteúdo ser apenas depositado em uma pequena parte do desenvolvimento intelectual do aluno. 


\section{Metodologia}

O presente trabalho foi organizado em quatro etapas. A primeira consiste em pesquisas e levantamentos bibliográficos, buscando referências acerca da prática pedagógica no ensino de Cartografia, parte fundamental para o embasamento teórico e a análise dos dados coletados. A segunda etapa estrutura-se na observação in loco da prática docente em sala de aula, objetivando entender a concepção cartográfica apresentada pelo professor. Foram selecionadas duas escolas estaduais do município de Três Lagoas (MS), onde foram escolhidos dois professores do Ensino Fundamental II $\left(6^{\circ}\right.$ ao $9^{\circ}$ ano $)$, sendo um de cada escola. A escolha dos docentes baseou-se na sua formação - ambos se formaram na UFMS, no campus de Três Lagoas, onde receberam uma formação completa e de qualidade, atuando hoje em escolas estaduais do município. O roteiro se estruturou em uma observação total de 40 horas de aula, sendo 20 horas para cada professor e considerando que ambos aplicaram uma avaliação em uma das aulas, totalizando, portanto, 38 horas de aula. Norteadas por questionamentos sobre o uso da cartografia nas aulas, o foco era ver se havia nelas algum uso cartográfico, tanto como conteúdo ou linguagem, considerados pressupostos para o embasamento teórico sobre a prática cartográfica no ensino de Geografia.

Para a observação foram estabelecidos pontos específicos da aula a serem analisados, como: quais recursos o docente utilizava em sala e a frequência e o método de uso do livro didático e dos mapas. Também foi observado se era feita uma leitura cartográfica dos conteúdos e como essa leitura era concebida pelo docente, se a Cartografia estava presente no processo de ensino e aprendizagem e como ela estava sendo tratada nesse processo. Esses são elementos-chave para a realização da terceira etapa: a organização e tabulação dos dados da etapa dois, realizando um gráfico que contabilize a frequência do uso e da leitura dos mapas em sala de aula, possibilitando, assim, a análise proposta neste trabalho. Essa etapa permitirá a sistematização da etapa quatro, que será a análise dos dados tabulados. Assim, a conclusão da análise sobre o papel da Cartografia para o ensino de geografia possibilitará a criação e a implementação de metodologias e materiais didáticos para o uso em sala de aula.

\section{Resultados E Discussões}

Foram observadas 20 aulas do professor A e 20 do professor B. Durante essas aulas, foi considerado para o relatório se algum mapa era usado em a cada aula e de que forma ele foi usado para o conteúdo ministrado, observando também se havia uma leitura do material ou se ele apenas era usado como uma figura ilustrativa do conteúdo, seguido de um texto e apresentado para localizar o fenômeno.

Ao final da carga horária de aula, foi contabilizada a quantidade do uso e da leitura de mapas, respondendo os questionamentos sobre o uso da Cartografia em sala de aula em números e elaborados gráficos para cada professor. Por meio desse trabalho, foi possível visualizar a frequência do uso do livro didático, partindo do conteúdo e da leitura com o intuito de interpretar o material gráfico. Os Gráficos 1 e 2 representam o uso e a leitura de mapas na prática em sala de aula do professor A.

Gráfico 1. Uso de Mapas na prática do professor A

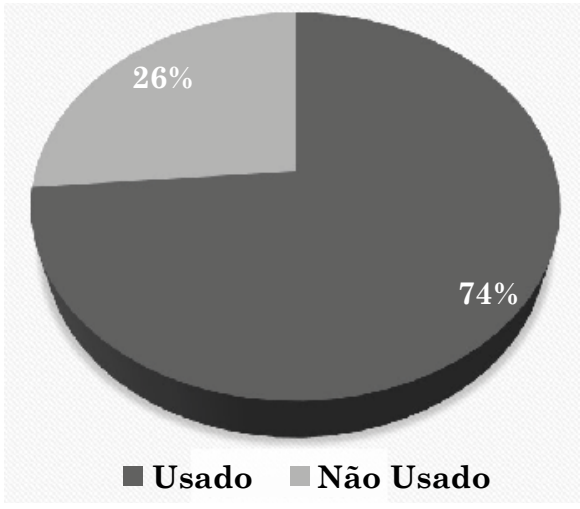

Fonte: Elaboração própria.

Gráfico 2. Leitura de mapa na prática do professor A

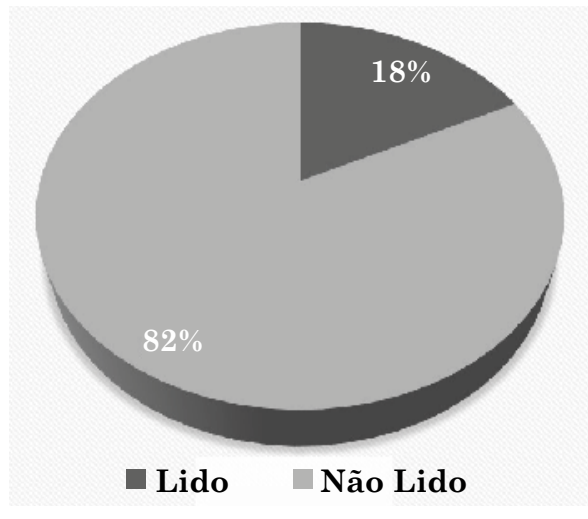

Fonte: Elaboração própria.

Nota-se no Gráfico 1 que o professor A usou o mapa com bastante frequência. Considerando as 20 aulas em que o trabalho do docente foi examinado - uma delas destinada à aplicação de avaliação - o docente A usou 
o mapa em 74\% das aulas. Contudo, o Gráfico 2 traz a frequência de leitura desses mapas: $74 \%$ - destacando ainda que os mapas usados eram apresentados no livro didático, pois a escola não tinha disponível globos e mapas verticais. Desses $74 \%$, em 18\% foi feita a leitura de mapas e em $82 \%$ não houve leitura; ou seja, o mapa foi utilizado, mas não houve uma leitura recorrente e aprofundada das informações, como título, legenda, escala e implementação para a obtenção de informações sobre o que estava representado. Sendo assim, percebe-se o papel da Cartografia concebido pelo professor A.

Nos Gráficos 3 e 4 serão apresentados os dados de uso e leitura do professor B.

Gráfico 3. Uso de Mapas na prática do professor B

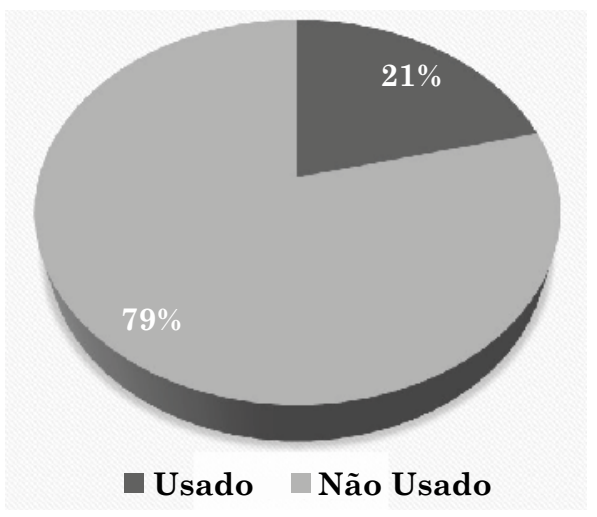

Fonte: Elaboração própria.

Gráfico 4. Leitura de mapa na prática do professor B

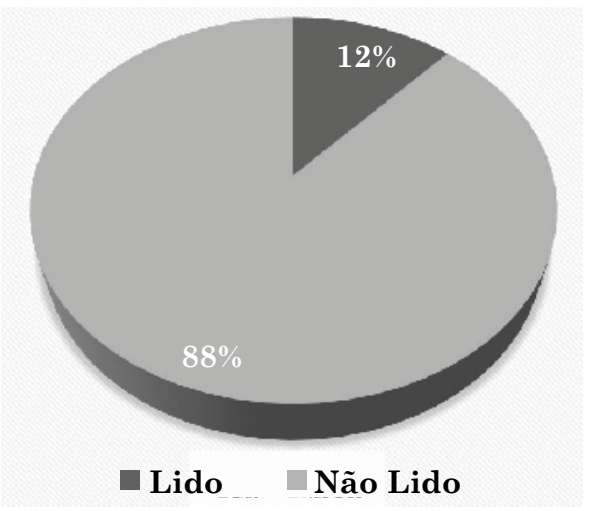

Fonte: Elaboração própria.

Analisando os gráficos do professor B, é notável a discrepância do uso de mapas quando comparado ao do professor A, já que B somente utilizou o mapa em $21 \%$ das aulas e, consequentemente, só houve leitura em $12 \%$. Sendo assim, destaca-se também a recorrência do livro didático e o uso dos mapas contidos nele Porém, o professor B não usou os mapas, tampouco os leu em sala de aula, ignorando a prática do ensino da Cartografia como uma linguagem para a ciência geográfica.

Diante das informações tabuladas, é possível e notória a prática cartográfica como um elemento secundário na geografia escolar. Considerando o uso intensivo dos livros didáticos que apresentam mapas de acordo com o conteúdo lecionado, seguido de um texto ou de uma pequena explicação, transformando também o elemento cartográfico como uma ferramenta adicional e secundária. Verifica-se com isso que a essência da Geografia em estudar os fenômenos no espaço está aquém do que se deseja no processo de ensino e aprendizagem.

\section{Conclusão}

Conclui-se neste trabalho que a Cartografia no ensino escolar da Geografia encontra-se ainda como elemento secundário, aparecendo em determinadas fases do processo de ensino como apenas um conteúdo técnico e conceitual a ser transmitido para os alunos. Nas práticas dos professores A e B, foi possível notar que o professor A faz mais uso de mapas que o professor B. Entretanto, nenhum deles tem o hábito de explorar o mapa com a linguagem cartográfica, incentivando a leitura e obtenção de dados para a interpretação e reflexão dos fenômenos representados no espaço. Cabe ressaltar que os dois fazem uso do livro didático, pois é o único material disponível nas escolas.

Observou-se também que o uso dos mapas durante as aulas tem o sentido apenas de localizar o fenômeno no espaço, ignorando outras questões chave, por exemplo: por que se localiza? Como se localiza? Quando se localiza? Esses e outros questionamentos permitem a reflexão sobre os fenômenos espaciais representados.

As cartas apresentadas durante a pesquisa in loco eram ricas e mostravam informações do espaço que podem ser mais eficientes do que uma explicação rasa dos conceitos geográficos, em forma de pequenos textos, fragmentando e limitando os recursos dispostos na geografia escolar.

Além das práticas docentes, outros fatores também podem ser mencionados sobre as aulas, pois nenhuma das escolas dispõe de mapas, globos, ou recursos tecnológicos. Contudo, vale salientar que os livros possuem mapas que podem auxiliar na realização da leitura e compreensão do mundo por meio da linguagem, pois isso consiste em uma forma de ler o mundo, ainda que não seja aquela do alfabeto, mas uma linguagem visual 
e geográfica, construindo, assim, o olhar sobre o espaço geográfico na formação do aluno como sujeito social, que também faz parte desse espaço.

A Cartografia é um recurso que precede a escrita e, assim como no período paleolítico, os desenhos dos lugares apresentavam informações ricas sobre o espaço e seu contexto histórico, e foram utilizados nos grandes triunfos das sociedades humanas. A Cartografia como ciência consiste em um dos símbolos do avanço do mundo e das representações gráficas. E, como linguagem, é o progresso do pensamento e de uma pessoa que consegue ler por meio de signos e interpretar grandes significados do espaço geográfico, compreendendo, então, a complexa relação do homem com a natureza, o que torna seus estudos únicos e necessários.

Para finalizar, é possível conceber uma cartografia diferente em sala de aula, com propostas metodológicas e materiais didáticos que elevem sua importância para qualquer conteúdo geográfico, dispondo sua linguagem como outra forma de leitura e compreensão do mundo.

\section{REFERÊNCIAS}

AUDIGIER, F. La géographie scolaire : un modèle disciplinaire puissant. In: KNAFOU, R. (org.). L'état de la géographie : autoscopie d'une science. Paris: Belin, 1997. p. 75-79.

BRASIL. Ministério da Educação. Base Nacional Comum Curricular. Brasília, DF: MEG, 2017. Disponível em: https://bit.ly/3qVHvyM. Acesso em: 7 jan. 2020.

BRASIL. Ministério de Educação. Secretaria de Educação Fundamental. Parâmetros Gurriculares Nacionais: terceiro e quarto ciclos do Ensino Fundamental -
Geografia. Brasília, DF: MEC/SEF, 1998. Disponível em: https://bit.ly/36kDqed. Acesso em: 6 jan. 2020.

CALLAI, H. C. Estudar o lugar para compreender o mundo. In: CASTROGIOVANNI, A. C. (org.). Ensino de geografia: práticas e textualizações no cotidiano. Porto Alegre: Mediação, 2000.

CAVALCANTI, L. S. A geografia e a realidade escolar contemporânea: avanços, caminhos, alternativas. In: SEMINÁRIO NAGIONAL: CURRÍCULO EM MOVIMENTO - Perspectivas Atuais, 1., 2010, Belo Horizonte. Anais [...]. Belo Horizonte: MEC, 2010. p. 1-16.

KATUTA, A. M. O ensino e aprendizagem das noções, habilidade e conceitos de orientação e localização geográficas: algumas reflexões. Revista do Departamento de Geociências da Universidade Estadual de Londrina, Londrina, v. 9, n. 1, p. 5-24, 2000.

MIRANDOLA, P. H. Cartografia e sistemas de informação geográfica: teoria e prática para representação de rotas turísticas: um exemplo aplicado à Rota Pantanal Pacífico - Brasil - Bolívia - Peru e Chile. 2010. Relatório (Pós-doutorado Júnior) - Universidade de São Paulo, São Paulo, 2010.

SANTOS, C.; PEDROTTI, A.; MATOS, A. L.; SANTANA, A. P. S. A Cartografia e o ensino da Geografia. Revista Geográfica de América Central, v. 2, n. 47, p. 1-15, 2011.

SIMIELLI, M. E. R. Cartografia no ensino fundamental e médio. In: CARLOS, A. F. A. (org). A Geografia na sala de aula. 8. ed. São Paulo: Contexto, 2007. 